\title{
THE EFFECTS OF MIXTURES OF VARIOUS CONCENTRATIONS OF CARBOXYMETHYL CHITOSAN/AMORPHOUS CALCIUM PHOSPHATE WITH GYPSUM ON DENTIN REMINERALIZATION
}

\author{
IKE DWI MAHARTI ${ }^{1}$, ENDANG SUPRASTIWI ${ }^{2 *}$, HASTI DWI SETIATI $^{3}$, ERLIYANA YAMIN $^{3}$, ANDI NURWALINI CAHYANI ${ }^{3}$ \\ ${ }^{1}$ Doctoral Program, Faculty of Dentistry, Universitas Indonesia, Jakarta, Indonesia. ${ }^{2}$ Department of Conservative Dentistry, Faculty \\ of Dentistry, Universitas Indonesia, Jakarta, Indonesia. ${ }^{3}$ Conservative Dentistry Residency Program, Faculty of Dentistry, Universitas \\ Indonesia, Jakarta, Indonesia. Email: esuprastiwi@yahoo.co.id
}

Received: 21 February 2020, Revised and Accepted: 01 June 2020

ABSTRACT

Objective: Carboxymethyl chitosan/amorphous calcium phosphate (CMC/ACP) is a non-collagen protein analog with the ability of dentin remineralization, and gypsum is a compound material than can facilitate application of CMC/ACP. CMC/ACP concentration is claimed to increase calcium and phosphate concentration, which indicates dentin remineralization. The aim of this study is to observe the effects of different concentrations of CMC/ACP mixed with gypsum on dentin remineralization.

Methods: Occlusal cavities were created in 18 freshly extracted teeth, and the teeth were divided into three groups. The first group consisted of untreated demineralized dentin, and the second and third groups were treated with mixtures of $2.5 \%$ and $5 \%$ CMC/ACP and gypsum. All groups were checked and analyzed on the $14^{\text {th }}$ day using scanning electron microscopy/energy-dispersive X-ray spectroscopy and one-way ANOVA (p<0.05).

Results: Significant differences ( $\mathrm{p}=0.001$ ) of calcium and phosphate concentrations were found between Groups I, II, and III ( $\mathrm{p}=0.001)$, whereas no differences were found between Groups II and III.

Conclusion: Gypsum and CMC/ACP work synergistically to induce dentin remineralization. The highest dentin remineralization was shown by $5 \%$ $\mathrm{CMC} / \mathrm{ACP}$-gypsum mixture, but the level was not statistically different from that of $2.5 \% \mathrm{CMC}$ /ACP-gypsum mixture.

Keywords: Carboxymethyl chitosan, Amorphous calcium phosphate, Gypsum, Calcium sulfate, Remineralization.

(c) 2020 The Authors. Published by Innovare Academic Sciences Pvt Ltd. This is an open access article under the CC BY license (http://creativecommons. org/licenses/by/4. 0/) DOI: http://dx.doi.org/10.22159/ijap.2020.v12s2.0P-15

\section{INTRODUCTION}

Gypsum, or calcium sulfate, is a biocompatible regenerative material that releases calcium ions. It is absorbed easily without inducing an inflammatory response [1,2]. Gypsum is often used as a compound material for medicines [3]. Amorphous calcium phosphate (ACP) is a saturated solution of calcium phosphate particles in amorphous form. As it acts as a bioapatite precursor in the transition phase of biomineralization, stabilizing it requires the use of an analogous material with several carboxyl groups, such as carboxymethyl chitosan (CMC), to bind the calcium ions [4,5]. Chen et al. [6] and Annisa [7] used CMC/ACP as the material for intrafibrillar dentin remineralization in vitro.

Moreover, Subhi et al. mixed gypsum with chitosan and bone morphogenetic protein 2 (BMP2) to create pulp capping materials [8]. They analyzed the physical, mechanical, and cellular properties of dental pulp stem cells (DPSCs) and obtained pH results close to neutral and a setting time and compressive strength that were both better than found with Dycal. The cellular analysis of DPSCs showed good viability and increased alkaline phosphatase activity on the $3^{\text {rd }}$ day [8].

Dentin remineralization is formed conventionally as guided tissue remineralization (GTR)/bottom-up/non-classical remineralization. GTR is a biomimetic mineralization process, with natural formation of mineral crystals and non-collagen proteins and no residual apatite. When the noncollagen protein has been damaged by caries, a substitute analog material is required to bring calcium and phosphate particles in amorphous form to the gap zone area [9]. Annisa et al. demonstrated that CMC/ACP can improve the GTR process [10]. Varying the CMC/ACP concentration can increase the dentin remineralization, with $2.5 \%$ being the optimum concentration [11]. In contrast, addition of gypsum to the CMC/ACP may facilitate its application on cavities. Therefore, using scanning electron microscopy (SEM)/energy-dispersive X-ray spectroscopy (EDX), this study analyzes the effects of various concentrations of CMC/ACP mixed with gypsum on dentin remineralization.

\section{METHODS}

This research was approved by the Dentistry Research Ethics Commission of the Faculty of Dentistry, Universitas Indonesia, with protocol number 051171218. Molar teeth without abnormalities were immersed after extraction in a solution containing phosphate-buffered saline (PBS) at $4^{\circ} \mathrm{C}$ and stored for 14 days. Three cavity samples were made in each tooth to obtain 18 cavities. Each cavity was inundated with $17 \%$ ethylenediaminetetraacetic acid (EDTA) solution (MD Cleanser ${ }^{\mathrm{TM}}$, Meta Biomed Co. Ltd., Chungbuk, Korea) for 1 week, stored in a shaker incubator $(100 \mathrm{rpm})$ at $37^{\circ} \mathrm{C}$, and rinsed with aquabidest for $30 \mathrm{~min}$. In addition, each cavity was inundated with $1 \mathrm{M} \mathrm{NaCl}$ solution $\left(\mathrm{pH} \mathrm{7.0)}\right.$ for $8 \mathrm{~h}$ at $25^{\circ} \mathrm{C}$.

We made a mixture of CMC/ACP and gypsum by heating the gypsum for $3 \mathrm{~h}$ at $110^{\circ} \mathrm{C}$ in an electric oven (Universal Oven Memmert Life 600 , Schwabach, Germany) to form a hemihydrate. The CMC/ACP was made as follows: $2.5 \mathrm{~g}$ of CMC (University of North Sumatra Research Center Laboratory, Medan, Indonesia) were mixed into $40 \mathrm{ml}$ of water. The mixture was stirred at $1000 \mathrm{rpm}$ until the $\mathrm{CMC}$ powder dissolved and a gel was formed. Next, $0.498 \mathrm{~g}$ of $\mathrm{K}_{2} \mathrm{HPO}_{4}$ was added to the gel, and the mixture was stirred at $500 \mathrm{rpm}$. Then, a mixture of $0.555 \mathrm{~g}$ of $\mathrm{CaCl}_{2}$ in $10 \mathrm{ml}$ deionized water was dropped slowly into the CMC gel, and the resultant mixture was stirred for 5 min until a CMC/ACP gel was formed. The solution was then frozen for $2 \mathrm{~h}$ at $-80^{\circ} \mathrm{C}$ and lyophilized 
by freeze-drying for $6 \mathrm{~h}$. This was followed by the production of a concentrated solution of $2.5 \%$ and $5 \%$ CMC/ACP ready to be mixed with $1 \mathrm{~g}$ of gypsum.

The 18 cavities were divided into three groups: Group I was demineralized dentin, Group II was application of $2.5 \%$ CMC/ACP-gypsum mixture, and Group III was application of 5\% CMC/ACP-gypsum mixture. The cavities were filled with light-curing temporary restoration, immersed in PBS solution, and stored in a shaker incubator for 14 days at $37^{\circ} \mathrm{C}$

All teeth were cut to the cavity base and fixed using a multilevel dehydration method. The samples were also soaked with $50 \%, 70 \%$, $80 \%$, and $90 \%$ ethanol for 20 min and $96 \%$ ethanol for $2 \mathrm{~h}$. The surfaces was coated with gold $(\mathrm{Au})$, and the morphology of the dentin surfaces was analyzed using a SEM connected with EDX (TESCAN VEGA3, BrnoKohoutovice, Czech Republic) to measure the content of calcium and phosphate ions. The data were analyzed using Integrated Calibration and Application Tool software (Oxford Instruments). EDX analysis of the cavity base was performed twice for each sample.

\section{RESULTS AND DISCUSSION}

Studies of CMC/ACP in gel-based preparation have proven that GTR can remineralize dentin within 14 days [6,7]. However, it is difficult for clinicians to apply the required additional material. Therefore, this study selected gypsum, due to its biocompatible and regenerative characteristics, as a CMC/ACP compound material to obtain applicable preparations.

Gypsum is a mineral that consists of calcium sulfate dihydrate $\left(\mathrm{CaSO}_{4} / 2 \mathrm{H}_{2} \mathrm{O}\right)$ and shows a good biological response. It is absorbed perfectly in vivo, with no inflammatory response and promotes the release of growth factors (BMP-2, BMP-7, transforming growth factor-beta, and platelet-derived growth factor), angiogenesis, and migration of fibroblasts, which improve the process of bone healing [1]. Moreover, as reported by Lewis et al., the addition of thick polymers (i.e., hyaluronan and CMC) improves the handling of gypsum and its mechanical properties [3]. The addition of CMC will enhance flexural and compressive strength. According to Reynolds et al., adding polymers to gypsum increases osteogenesis and calcification, also affects bone regeneration [3].

The addition of gypsum to the CMC/ACP gel will form a paste with a smooth texture, making it easy to put on cavity. Subhi et al. showed that a mixture of gypsum, CMC/ACP, and BMP-2 as a pulp-capping material increased alkaline phosphatase activity on the $3^{\text {rd }}$ day [8]. Erliyana et al. also analyzed that adding gypsum to $5 \% \mathrm{CMC} / \mathrm{ACP}$ concentration could increase the remineralization of dentin, but the results were not significant [11]. Increasing CMC concentration in the ACP mixture improved its remineralization ability, and the concentration of $2.5 \%$ CMC showed significant results [12].

In this study, the demineralized dentin was used as a sample which imitated clinical condition. Approximately 17\% EDTA was chosen as the demineralization material for its chelation ability against calcium ions, using crosslinking of intact collagen [13].

EDX (EDS and EDAX) is used to analyze either chemical elements or the characteristics of specimens. Each element has a unique atomic structure that allows its identification by X-rays.

Statistical analysis was conducted using Statistical Package for the Social Sciences 22 software. The phosphate and calcium concentrations were analyzed using one-way ANOVA and the between-group comparisons were made using the post hoc Tamhane test with a significance level of $\mathrm{p}<0.05$. The highest average value of calcium and phosphate (Table 1 ) was observed with $5 \% \mathrm{CMC} / \mathrm{ACP}$-gypsum mixture (Group III), the next highest value was observed with $2.5 \%$ CMC/ACP-gypsum mixture (Group II), and the lowest value was observed with the demineralized dentin (Group III). Both calcium and phosphate show significant increases between groups.

The average values of calcium and phosphate increased in Groups II and III and also in the mixtures of gypsum and CMC/ACP. This suggests that gypsum and CMC/ACP work synergistically to induce remineralization of dentin. From Group I (demineralized dentin stored for 14 days in a shaker incubator) to Group II (demineralized dentin with 2.5\% $\mathrm{CMC}$ /ACP-gypsum mixture), there was a significant increase in both calcium and phosphate because of the addition of gypsum, which also contains calcium.

In Table 2, there are significant differences in the values between Group I and Group II ( $p=0.019)$ and between Group I and Group III ( $\mathrm{p}=0.001)$. However, there are no significant differences in values between Group II and Group III ( $\mathrm{p}=0.394)$.

Moreover, Table 3 shows significant differences in the values for phosphate groups between Group I and Group II ( $\mathrm{p}=0.05)$ and between Group I and Group III $(\mathrm{p}=0.01)$, whereas there are no significant differences between Group II and Group III ( $\mathrm{p}=0.921)$.

Table 1: Mean value, standard deviation, and significance of calcium (\%) and phosphate (\%) in each group

\begin{tabular}{llll}
\hline Group & $\mathbf{n}$ & Mean (SD) & p \\
\hline Calcium & & & \\
$\quad$ Group I & 6 & $22.38(1.67)$ & $0.001^{*}$ \\
Group II & 6 & $37.81(1.73)$ & \\
$\quad$ Group III & 6 & $11.57(0.45)$ & $0.001^{*}$ \\
Phosphate & & $17.29(0.89)$ & \\
$\quad$ Group I & 6 & $17.68(0.32)$ & \\
Group II & 6 & & \\
Group III & 6 & &
\end{tabular}

*One-way ANOVA test $\mathrm{p}<0.05$

Table 2: Mean value of differences between calcium groups

\begin{tabular}{lll}
\hline Group & Group II & Group III \\
\hline Group I & $0.019^{*}$ & $0.001^{*}$ \\
Group II & & 0.394 \\
\hline
\end{tabular}

*Post hoc Tamhane test $\mathrm{p}<0.05(*)$

Table 3: Mean value of differences between phosphate groups

\begin{tabular}{lll}
\hline Group & Group II & Group III \\
\hline Group I & $0.005^{*}$ & $0.001^{*}$ \\
Group II & & 0.921 \\
\hline
\end{tabular}

*Post hoc Tamhane test $\mathrm{p}<0.05\left({ }^{*}\right)$

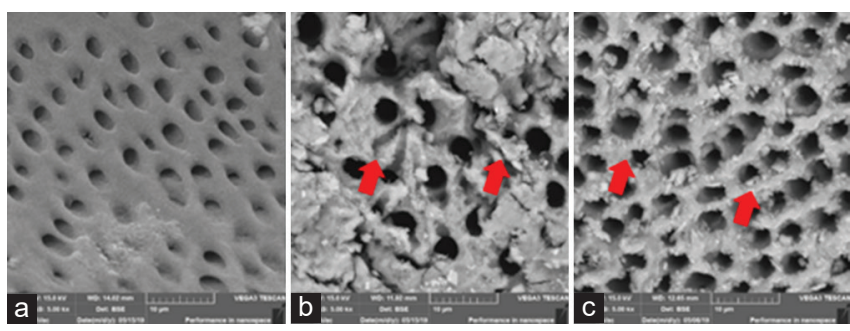

Fig. 1: Scanning electron microscopy results of each group with $\times 5000$. (a) Demineralized dentin, (b) demineralized dentin with $2.5 \%$ carboxymethyl chitosan (CMC)/amorphous calcium phosphate (ACP)-gypsum mixture, (c) demineralized dentin with $\mathbf{5 \%}$

CMC/ACP-gypsum mixture. The remineralization denoted by the red arrows shows the irregular shape of the dentinal tubule walls 
In analyzing the significance values between the groups, both calcium and phosphate ions showed a mixture of gypsum, with a significant increase in CMC/ACP amount and phosphate ions. Calcium and phosphate ions can form a hydroxyapatite precursor that allows the ions to enter a narrow yet complex area in the dentin structure. However, the formation of hydroxyapatite is not always preceded by an apatite precursor. ACP is one of the hydroxyapatite precursors [14]. Moreover, the concentration between $2.5 \%$ and $5 \%$ despite the differences in values was not statistically significant (Tables 2 and 3). However, to verify this, further research using transmission electron microscope observation is required.

Fig. 1 shows different SEM images of the surface morphology among untreated demineralized dentin (a), demineralized dentin after application of $2.5 \%$ CMC/ACP-gypsum mixture (b), and demineralized dentin after application of 5\% CMC/ACP-gypsum mixture (c). Untreated demineralized dentin shows the thickened dentin and intratubular walls, while demineralized dentin after application of $2.5 \%$ CMC/ACP-gypsum mixture shows the mineral deposits on dentinal tubule walls; and the one after application of 5\% CMC/ACP-gypsum mixture shows denser mineral deposits with more irregular edges of dentin tubules.

\section{CONCLUSION}

About $2.5 \%$ and $5 \%$ CMC/ACP and gypsum mixtures tended to enhance the dentin remineralization process to the same extent, characterized by an increase in the concentration of calcium and phosphate ions and morphological changes on the dentin surface. Although 5\% CMC/ACP-gypsum mixture showed higher dentin remineralization, the difference was not significant

\section{ACKNOWLEDGMENT}

The researchers wish to express their profound gratitude to the Research Centre Laboratory of Universitas Sumatera Utara for providing the CMC material used in this research.

\section{CONFLICTS OF INTEREST}

The authors declare no conflicts of interest.

\section{REFERENCES}

1. Jang Y, Kim H, Roh D. Biologic response of local hemostatic agents used in endodontic microsurgery. Restor Dent Endod 2014;7658:79-88.

2. Ulusoy AT, Bayrak S, Bodrumlu EH. Clinical and radiological evaluation of calcium sulfate as direct pulp capping material in primary teeth. Eur J Paediatr Dent 2014;15:127-31.

3. Thomas MV, Puleo DA. Review calcium sulfate : Properties and clinical applications. J Biomed Mater Res B Appl Biomater 2009;88:597-610.

4. Narayanan D, Jayakumar R, Chennazhi KP. Versatile carboxymethyl chitin and chitosan nanomaterials : A review. Nanomed Nanobiotechnol 2014;6:574-98.

5. Zargar V, Asghari M, Dashti A. A review on chitin and chitosan polymers : Structure, chemistry, solubility, derivatives, and applications. ChemBioEng Rev 2015;2:1-24.

6. Chen Z, Cao S, Wang H, Li Y, Kishen A, Deng X. Biomimetic remineralization of demineralized dentine using scaffold of CMC/ACP nanocomplexes in an in vitro tooth model of deep caries. PLoS One 2015;10:1-19.

7. Annisa RN. Potensi Carboxymethyl Chitosan/Amorphous Calcium Phosphate (cmc/acp) Pada Remineralisasi Intrafibrillar Kolagen Dentin, Thesis. Jakarta, ID: Universitas Indonesia; 2018.

8. Subhi H, Reza F, Husein A, Al Syehadat SA, Nurul AB. Gypsum-based material for dental pulp capping: Effect of chitosan and gypsumbased material for dental pulp capping : Effect of chitosan and BMP2 on physical, mechanical, and cellular properties. Int J Biomater 2018;2018:3804293.

9. Cao CY, Mei ML, Li Q, Chin E, Lo M, Chu CH. Methods for biomimetic remineralization of human dentine : A systematic review. Int J Mol Sci 2015;16:4615-27.

10. Annisa R, Djauharie N, Suprastiwi E, Avanti N. The effect of carboxymethyl chitosan/amorphous calcium phosphate to guide tissue remineralization of dentin collagen. Int J Appl Pharm 2019;11:181-83.

11. Yamin E, Suprastiwi E, Usman M, Hasim S. Effects of Gypsum Addition on CMC/ACP on the Ability to Remineralize Dentin, Thesis. Jakarta, ID: Universitas Indonesia; 2019.

12. Setiati HD, Suprastiwi E, Artiningsih D, Utami LP. The Effect of Carboxymethyl Chitosan Concentration on Amorphous Calcium Phosphate Ability to Remineralize Dentin, Thesis. Jakarta, ID: Universitas Indonesia; 2019.

13. Mohammadi Z, Shalavi S, Jafarzadeh H. Ethylenediaminetetraacetic endodontics acid in endodontics. Eur J Dent 2013;1:S135-42.

14. Combes C. Apatite biominerals. Minerals 2016;6:34. 